\title{
Synthesis and Properties of Dumbbell-Shaped Dendrimers Containing 9-Phenylcarbazole Dendrons
}

\author{
Ken-Tsung Wong, ${ }^{*}$ Yu-Hsien Lin, Hsu-Hsuan Wu, and Fernando Fungo \\ Department of Chemistry, National Taiwan University, Taipei 106, Taiwan, and \\ Departamento de Química, Universidad Nacional de Río Cuarto, Agencia Postal 3 \\ (5800), Río Cuarto, Argentina
}

kenwong@ntu.edu.tw

Received August 21, 2007

\section{ABSTRACT}

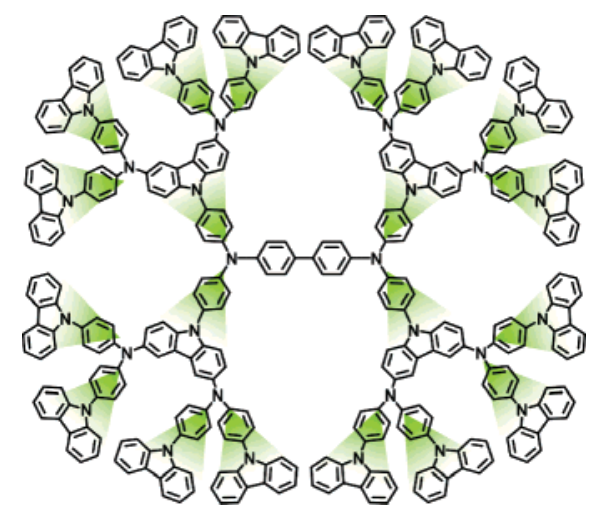

We report the synthesis and structural characterization of two dumbbell-shaped dendrimers incorporating 9-phenylcarbazole units as dendrons, as well as their thermal, morphological, photophysical, and electrochemical properties.

Dendrimers are monodispersed macromolecules possessing well-defined branched structures that can be precisely tailored with discrete and designated functionality to create multifunctional materials. Their unique structures and properties make dendrimers suitable subjects for a wide range of biomedical and industrial applications, such as drug delivery, ${ }^{1}$ multivalent bioconjugates ${ }^{2}$ and multivalent diagnostics for magnetic resonance imaging (MRI), ${ }^{3}$ extremely efficient

* Address correspondence to this author at National Taiwan University. (1) (a) Svenson, S.; Tomalia, D. A. Adv. Drug Delivery Rev. 2005, 57, 2106. (b) Najlah, M.; D'Emanuele, A. Curr. Opin. Pharmacol. 2006, 6, 522.

(2) (a) Baars, M. W. P. L.; Karlsson, A. J. K.; Sorokin, V.; de Waal, B. F. W.; Meijer, E. W. Angew. Chem., Int. Ed. 2000, 39, 4262. (b) Wu, P.; Malkoch, M.; Hunt, J. N.; Vestberg, R.; Kaltgrad, E.; Finn, M. G.; Fokin, V. V.; Sharpless, K. B.; Hawker, C. J. Chem. Commun. 2005, 5775.

(3) (a) Wiener, E. C.; Brechbiel, M. W.; Brothers, H.; Magin, R. L.; Tomalia, D. A.; Lauterbur, P. C. Magn. Reson. Med. 1994, 31, 1. (b) Caravan, P.; Thomas, J. E.; McMurry, T. J.; Lauffer, R. B. Chem. Rev. 1999, 99, 2293. light-harvesting antennae, ${ }^{4}$ and homogeneous catalysis. ${ }^{5}$ Recently, dendrimers have also found promising applications as materials for organic electronic devices, such as organic light-emitting diodes (OLEDs). ${ }^{6}$ Among the various types of dendrimers, carbazole-based dendrimers have emerged as a new family of intriguing materials that possess several attractive properties. For example, the fully conjugated 9-phenylcarbazole monodendrons synthesized by Moore and co-workers exhibit fluorescence quenching effects via throughspace interactions. ${ }^{7}$ Carbazole-based dendrons that have been incorporated at antennal positions surrounding porphyrin

(4) (a) Nantalaksakul, A.; Reddy, D. R.; Bardeen, C. J.; Thayumanavan, S. Photosynth. Res. 2006, 87, 133. (b) Balzani, V.; Ceroni, P.; Maestri, M.; Vicinelli, V. Curr. Opin. Chem. Biol. 2003, 7, 657.

(5) (a) Astruc, D. Pure Appl. Chem. 2003, 75, 461. (b) van Koten, G.; Jastrzebski, J. T. B. H. J. Mol. Catal. A: Chem. 1999, 146, 317.

(6) (a) Shirota, Y. J. Mater. Chem. 2000, 10, 1. (b) Burn, P. L.; Lo, S.-C.; Samuel, I. D. W. Adv. Mater. 2007, 19, 1675.

(7) (a) Zhu, Z.; Moore, J. S. J. Org. Chem. 2000, 65, 116. (b) Zhu, Z.; Moore, J. S. Macromolecules 2000, 33, 801. 

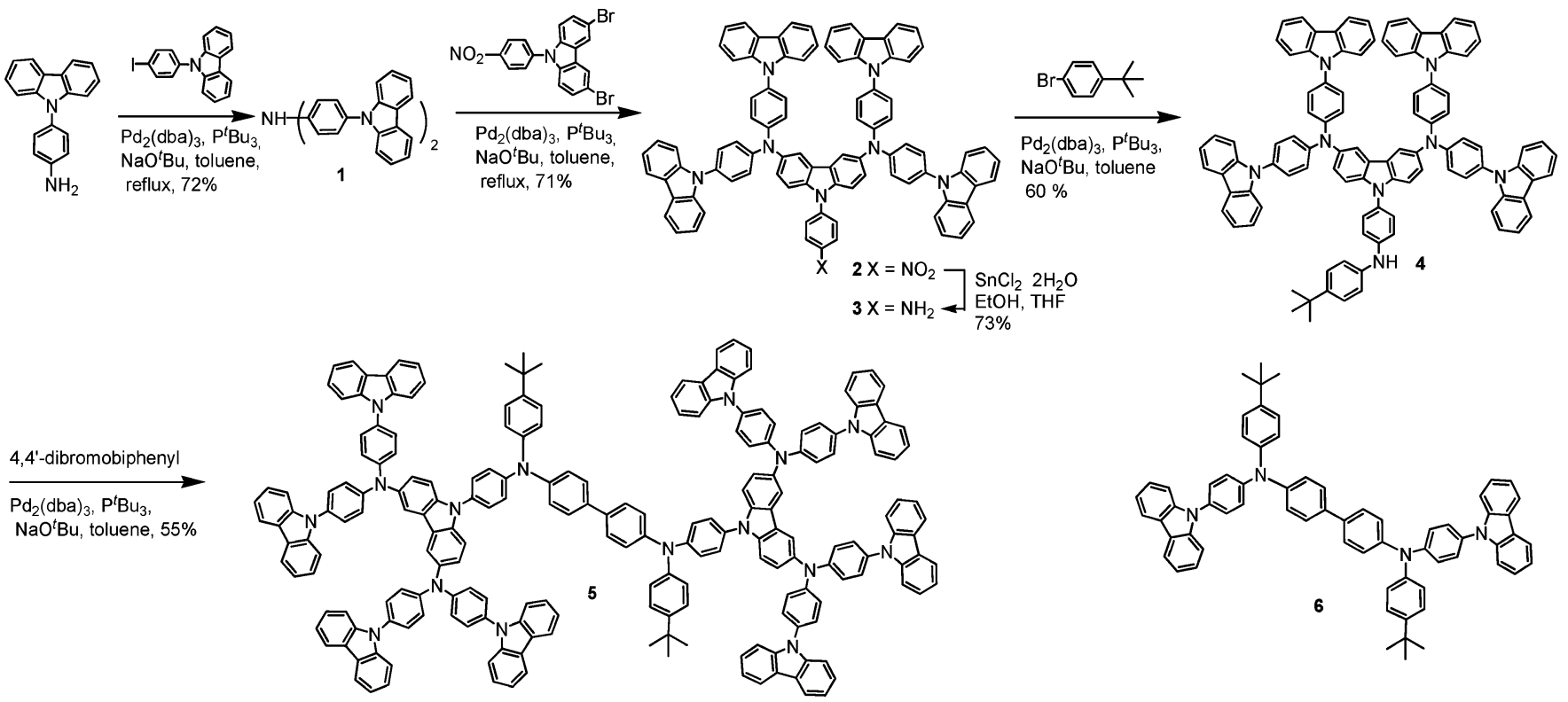

centers $^{8}$ and $\mathrm{Ru}(\mathrm{II})$-complex cores $^{9}$ mediate highly efficient energy transfer; they have also been employed as effective charge transporting moieties for iridium-based phosphorescent emitters. ${ }^{10}$ Dendrimers equipped with carbazole-based dendrons are promising materials for use as efficient holetransporting materials in OLEDs. ${ }^{11}$ Most carbazole-based dendrimers, except for those reported by $\mathrm{Moore}^{7}$ and Dehaen, ${ }^{12}$ have been prepared through formation of $\mathrm{C}-\mathrm{N}$ linkages, coupling the nitrogen atoms of an external carbazole unit to the active $\mathrm{C} 3$ and $\mathrm{C} 6$ sites of an inner carbazole moiety. Here we report the convergent synthesis (through efficient $\mathrm{C}-\mathrm{N}$ bond coupling reactions) and physical characterization of two novel dumbbell-shaped carbazolecontaining dendrimers incorporating 9-phenylcarbazole dendrons. Carbazole derivatives exhibit high triplet energy and are capable of transporting hole, thus, these new carbazolecontaining dendrimers may present interesting applications as efficient hole-transporters as well as host materials in electrophosphorescence devices.

Scheme 1 outlines our synthesis of the 9-phenylcabazolebased dendrons. The generational growth began with connection of the phenylene rings of two 9-phenylcabazole molecules through Pd-catalyzed $\mathrm{C}-\mathrm{N}$ bond formation between 9-(4-aminophenyl)carbazole and 9-(4-iodophenyl)-

(8) (a) Loiseau, F.; Campagna, S.; Hameurlaine, A.; Dehaen, W. J. Am. Chem. Soc. 2005, 127, 11352. (b) Xu, T. H.; Lu, R.; Qiu, X. P.; Liu, X. L.; Xue, P. C.; Tan, C. H.; Bao, C. Y.; Zhao, Y. Y. Eur. J. Org. Chem. 2006, 4041.

(9) McClenaghan, N. D.; Passalacqua, R.; Loiseau, F.; Campagna, S.; Verheyde, B.; Hameurlaine, A.; Dehaen, W. J. Am. Chem. Soc. 2003, 125, 5356.

(10) (a) Lo, S.-C.; Namdas, E. B.; Shipley, C. P.; Markham, J. P. J.; Anthopolous, T. D.; Burn, P. L.; Samuel, I. D. W. Org. Electron. 2006, 7. 85. (b) Zhou, G.; Wong, W.-Y.; Yao, B.; Xie, Z.; Wang, L. Angew. Chem., Int. Ed. 2007, 46, 1149

(11) (a) Kimoto, A.; Cho, J.-S.; Higuchi, M.; Yamamoto, K. Macromol. Symp. 2004, 209, 51. (b) Kimoto, A.; Cho, J.-S.; Ito, K.; Aoki, D.; Miyake, T.; Yamamoto, K. Macromol. Rapid Commun. 2005, 26, 597.

(12) Hameurlaine, A.; Dehaen, W. Tetrahedron Lett. 2003, 44, 957. carbazole $^{13}$ to afford the G1-N-G1 system 1 in good yield. Using the same synthetic protocol, we coupled compound 1 with 3,6-dibromo-9-(4-nitrophenyl)carbazole, which we had synthesized in moderate yield through the bromination of 9-(4-nitrophenyl)carbazole with $\mathrm{Br}_{2}$, to give the nitrosubstituted G2 dendron 2 in good yield. Reduction of the nitro group of 2 with $\mathrm{SnCl}_{2}$ gave a good yield of the aminoG2 dendron 3, which we further coupled with 1-bromo-4tert-butylbenzene to afford the unsymmetrical dendron $\mathbf{4}$ in moderate yield. Linking this dendron to $4,4^{\prime}$-didromobiphenyl provided a moderate yield of the unsymmetrical dumbbellshaped dendrimer 5. For comparison, we synthesized the G1derived counterpart $\mathbf{6}$ in a similar two-step synthetic route with a total yield of $70 \%$ (see the Supporting Information).

Although we were unable to convert the primary amino group of $\mathbf{3}$ into an iodo moiety, we did prepare the triflatesubstituted G2 derivative 7 (Scheme 2) as an electrophilic variant of that dendron. Coupling of the G1-N-G1 species 1 with 3,6-dibromo-9-(4-methoxyphenyl)carbazole gave a high yield of the methoxy-substituted dendron $\mathbf{8}$, the methyl group of which we subsequently removed through treatment with $\mathrm{BBr}_{3}$ to afford a high yield of the hydroxy-substituted G2 dendron 9. Treatment of 9 with triflic anhydride gave the desired pseudohalogen-substituted G2 dendron 7 in good yield. $\mathrm{C}-\mathrm{N}$ coupling of the amino- and triflate-substituted G2 dendrons 3 and 7 in the presence of $\operatorname{Pd}_{2}(\mathrm{dba})_{3}$ as catalyst and 2-(di-tert-butylphosphine)biphenyl as cocatalyst provided a moderate yield of the G2-N-G2 dendron $\mathbf{1 0}$.

Our attempts at coupling this G2-N-G2 dendron with 4,4'dibromobiphenyl or the more reactive $4,4^{\prime}$-diiodobiphenyl under the conditions of $\mathrm{Pd}$-catalyzed $\mathrm{C}-\mathrm{N}$ bond formation produced complicated mixtures of products. Gratifyingly, conventional Ullmann conditions $\left(\mathrm{Cu}, \mathrm{K}_{2} \mathrm{CO}_{3}\right.$, dichloroben-

(13) Chen, Y.-C.; Huang, G.-S.; Hsiao, C.-C.; Chen, S.-A. J. Am. Chem Soc. 2006, 128, 8549 . 
Scheme 2
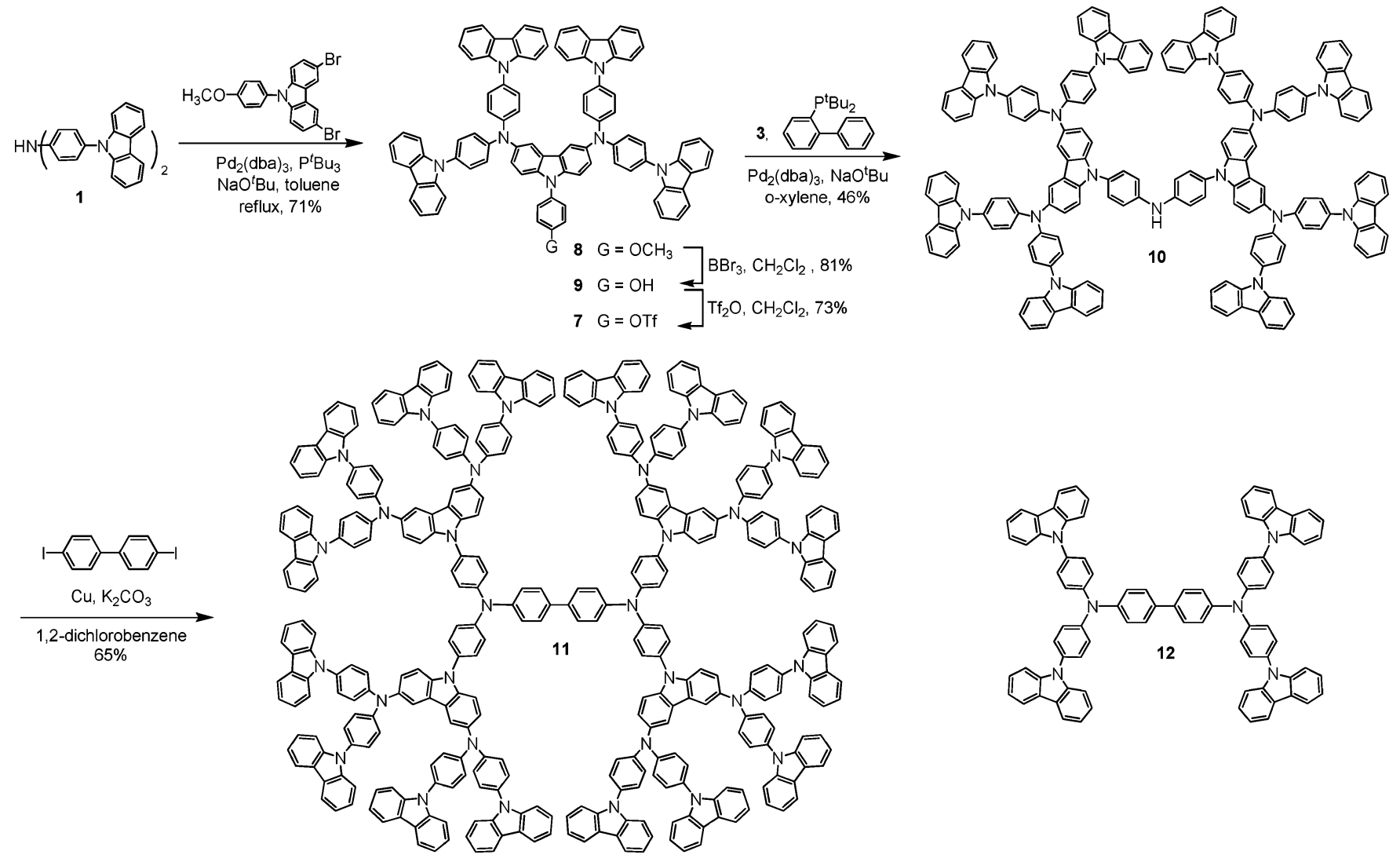

zene) allowed us to react the G2-N-G2 dendron 10 with 4,4'diiodobiphenyl to form the symmetrical dumbbell-shaped dendrimer $\mathbf{1 1}$ in good yield. As compare to the unsymmetrical 5, the symmetric 11 could provide different morphology in solid films, which is an important parameter governing the charge mobility in organic electronic devices. For comparison, we synthesized the G1-derived counterpart 12 in high yield through $\mathrm{Pd}$-catalyzed $\mathrm{C}-\mathrm{N}$ bond formation reactions between the G1-N-G1 system 1 and 4,4'-dibromobiphenyl (see the Supporting Information).

We obtained satisfactory spectroscopic and MALDI-TOF mass spectrometric (Figure S-1, Supporting Information) data that were consistent with the structural identity of the high molecular weight dendron 10, the unsymmetrical dumbbellshaped dendrimer 5, and the symmetrical dumbbell-shaped dendrimer 11. Table 1 summarizes the results of thermogravimetric analysis (TGA) and differential scanning calorimetry (DSC) measurements of the various compounds. We attribute the observed increased thermal and morphological stabilities of $\mathbf{5}$ and $\mathbf{1 1}$-relative to those of their low molecular weight counterparts $\mathbf{6}$ and 12, respectively-to their greater molecular weights.

Figure 1 provides a comparison of the electronic absorption and fluorescence spectra of the unsymmetrical dumbbellshaped dendrimer $\mathbf{5}$, the symmetrical dendrimer $\mathbf{1 1}$, and their respective counterparts $\mathbf{6}$ and $\mathbf{1 2}$.

The UV-vis spectra of these compounds exhibit the absorption characteristics (peaks at 294, 328, and $345 \mathrm{~nm}$ ) of their phenylcarbazole moieties, with the absorbance intensity increasing along with an increase in the number of phenylcarbazole units per molecule. We ascribe the absorptions at wavelengths exceeding $350 \mathrm{~nm}$ to the presence of the tetraphenylbenzidine (TPB) cores. ${ }^{14}$ The photoluminescence spectra of $\mathbf{6}$ and $\mathbf{1 2}$ display the typical emission characteristics of TPB moieties. The corresponding spectra of the dendrimers $\mathbf{5}$ and $\mathbf{1 1}$ exhibit slightly red-shifted emission wavelengths, centered at 433 and $438 \mathrm{~nm}$, respectively, relative to those of their counterparts 6 and $\mathbf{1 2}$. Because the G2-N-G2 dendron 10, which lacks a TPB chromophore, displays an emission maximum centered at

Table 1. Physical Properties of Dendrimers 5 and $\mathbf{1 1}$ and Their Low Molecular Weight Counterparts $\mathbf{6}$ and $\mathbf{1 2}$

\begin{tabular}{lcccc}
\hline & $\begin{array}{c}T_{\mathrm{g}} / T_{\mathrm{d}} \\
\left({ }^{\circ} \mathrm{C}\right)^{a}\end{array}$ & $\begin{array}{c}\mathrm{UV}-\mathrm{vis} \lambda_{\max } \\
(\mathrm{nm})^{b}\end{array}$ & $\begin{array}{c}\mathrm{PL} \lambda_{\max } \\
(\mathrm{nm})^{c}\end{array}$ & $\begin{array}{c}E_{1 / 2}{ }^{\text {oxd }} \\
(\mathrm{V})^{d}\end{array}$ \\
\hline $\mathbf{5}$ & $269 / 559$ & $294,330,345$ & 433 & $0.71,0.92$ \\
$\mathbf{6}$ & $158 / 459$ & $294,328,345$ & 412 & $0.70,0.90$ \\
$\mathbf{1 1}$ & $296 / 579$ & $294,330,345$ & 438 & $0.72,0.96$ \\
$\mathbf{1 2}$ & $195 / 546$ & $294,328,345$ & 416 & $0.73,0.86^{e}$
\end{tabular}

${ }^{a} T_{\mathrm{d}}=5 \%$ weight loss temperature. ${ }^{b}$ Measured from a $1.0 \times 10^{-6} \mathrm{M}$ solution in $\mathrm{CH}_{2} \mathrm{Cl}_{2}$. ${ }^{c}$ Measured from a $1.0 \times 10^{-6} \mathrm{M}$ solution in $\mathrm{CH}_{2} \mathrm{Cl}_{2}$, excited at $330 \mathrm{~nm}$. ${ }^{d}$ Measured from a $1.0 \times 10^{-3} \mathrm{M}$ solution in $\mathrm{CH}_{2} \mathrm{Cl}_{2}$ containing $0.1 \mathrm{M} \mathrm{Bu}_{4} \mathrm{NPF}_{6}$ as the supporting electrolyte and with use of a glassy carbon electrode. ${ }^{e}$ Measured with a Pt electrode and $0.1 \mathrm{M} \mathrm{Bu}_{4} \mathrm{NClO}_{4}$ as the supporting electrolyte. 


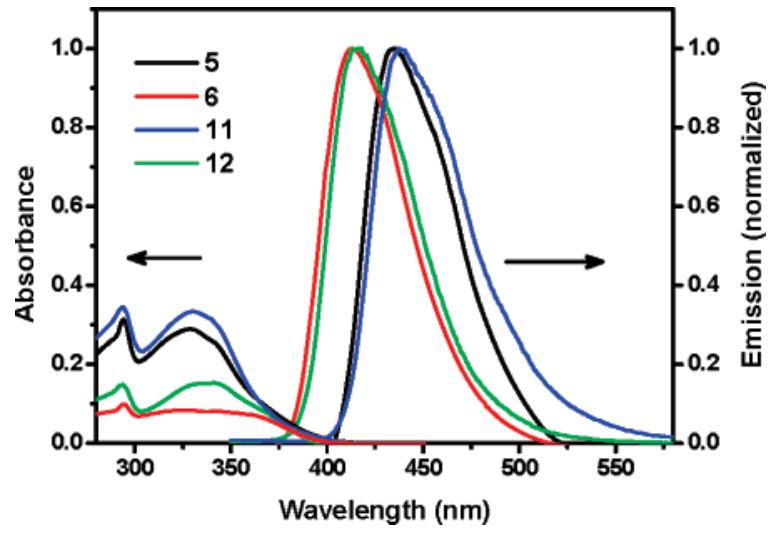

Figure 1. UV-vis absorption and photoluminescence spectra of the high molecular weight dendrimers $\mathbf{5}$ and $\mathbf{1 1}$ and their respective low molecular weight counterparts $\mathbf{6}$ and $\mathbf{1 2}$.

$436 \mathrm{~nm}$, the long-wavelength fluorescence observed for $\mathbf{5}$ and $\mathbf{1 1}$ can be unambiguously attributed as arising mainly from the lowest $\pi-\pi^{*}$ transition of the 3,6-diamino-9phenylcarbazole chromophore.

We used cyclic voltammetry (CV) to characterize the electrochemical properties of the high molecular weight dendrimers $\mathbf{5}$ and $\mathbf{1 1}$ and their low molecular weight counterparts $\mathbf{6}$ and $\mathbf{1 2}$. When the $\mathrm{CV}$ scanning range was between 0 and $1.2 \mathrm{~V}$ (vs $\mathrm{Ag} / \mathrm{AgCl}$ )- using a glassy carbon electrode as the working electrode in $\mathrm{CH}_{2} \mathrm{Cl}_{2}$ and $0.1 \mathrm{M} \mathrm{Bu}_{4^{-}}$ $\mathrm{NPF}_{6}$ as the supporting electrolyte-we observed two reversible oxidation potentials (at ca. 0.70 and $0.90 \mathrm{~V}$ ) for the dendrimers 5, 6, and 11. In contrast, the CV trace of $\mathbf{1 2}$ under the same conditions displayed a peak typical of a product adsorbed weakly onto the electrode surface (Figure S-2, Supporting Information). The two reversible oxidations of 12 were recovered when using a Pt working electrode (Figure S-3, Supporting Information). It appears quite reasonable to assign these potentials of the dendrimers $\mathbf{6}$ and $\mathbf{1 2}$ to the successive oxidations of the TPB-like cores. Because carbazoles lacking substituents at the $\mathrm{C} 3$ and $\mathrm{C} 6$ positions normally undergo oxidation at higher potentials, the presence of oxidized carbazole moieties usually leads to polymeric materials. ${ }^{15}$ Indeed, the consecutive increases in the response currents, together with the oxidation peaks shifting to lower

(14) Koene, B. E.; Loy, D. E.; Thompson, M. E. Chem. Mater. 1998, $10,2235$. potentials, over multiple $\mathrm{CV}$ scans $(0-1.6 \mathrm{~V})$ for dendrimers $\mathbf{5 , ~ 6}$, and $\mathbf{1 1}$ are good indicators that electropolymerization occurred at the peripheral carbazole groups (Figure S-2, Supporting Information). Accordingly, oxidation of the carbazole groups can be excluded from the contributions to the first two oxidation potentials of dendrimers $\mathbf{5}$ and 11, which contain four oxidizable sites (the four different nitrogen atom centers). Furthermore, the $\mathrm{CV}$ trace of dendron 10 revealed two reversible oxidation potentials, at 0.71 and $0.89 \mathrm{~V}$, respectively (Figure S-3, Supporting Information), which we suggest may be ascribed to the oxidations of the more-electron-rich 3,6-diaminocarbazole moiety. Because the oxidation potentials of $\mathbf{1 0}$ are similar to those of the TPBlike core of dendrimer $\mathbf{6}$, it is difficult to accurately determine the origins of the first two oxidation potentials detected for dendrimers 5 and 11. Nevertheless, our results indicate that the inner chromophores (i.e., TPB or 3,6-diaminocarbazole) have lower oxidation potentials, whereas the outer carbazole moieties oxidize at higher potentials; thus an intriguing redox gradient of electroactive dendrimers can be achieved, ${ }^{16}$ which may facilitate the hole migration from the core to the peripheral carbazoles

In summary, using efficient $\mathrm{C}-\mathrm{N}$ bond formation reactions and a convergent strategy, we have synthesized two dumbbell-shaped dendrimers (5 and 11) containing 9-phenylcarbazole units as dendrons and have characterized their structures and photophysical and electrochemical properties. The application of these dendrimers as hole-transporting and host material in organic optoelectronic devices is currently under investigation.

Acknowledgment. This study was supported financially by the National Science Council and Ministry of Education of Taiwan.

Supporting Information Available: Detailed experimental procedures, spectroscopic characterization of new compounds, MALDI-TOF mass spectra of compounds 5, 10, and 11, and cyclic voltammograms of compounds $5, \mathbf{6}, \mathbf{1 0}$, 11, and 12. This material is available free of charge via the Internet at http://pubs.acs.org.

OL702060U

(15) (a) Ambrose, J. F.; Carpenter, L. L.; Nelson, R. F. J. Electrochem Soc. Electrochem. Sci. Technol. 1975, 122, 876. (b) Natera, J.; Otero, L.; Sereno, L.; Fungo, F.; Wang, N.-S.; Tsai, Y.-M.; Hwu, T.-Y.; Wong, K.T. Macromolecules 2007, 40, 4456.

(16) (a) Selby, T. D.; Blackstock, S. C. J. Am. Chem. Soc. 1998, 120, 12155. (b) Li, Z.; Wong, M. S. Org. Lett. 2006, 8, 1499. 